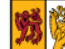 \\ People with dementia and caregiver preferences for digital life story work service interventions \\ O' Philbin, Laura; Woods, Robert; Holmes, Emily
}

\section{Aging and Mental Health}

DOI:

$10.1080 / 13607863.2018 .1525606$

Published: 01/02/2020

Peer reviewed version

Cyswllt i'r cyhoeddiad / Link to publication

Dyfyniad o'r fersiwn a gyhoeddwyd / Citation for published version (APA):

O' Philbin, L., Woods, R., \& Holmes, E. (2020). People with dementia and caregiver preferences for digital life story work service interventions: A discrete choice experiment and digital survey. Aging and Mental Health, 24(2), 353-361. https://doi.org/10.1080/13607863.2018.1525606

\section{Hawliau Cyffredinol / General rights}

Copyright and moral rights for the publications made accessible in the public portal are retained by the authors and/or other copyright owners and it is a condition of accessing publications that users recognise and abide by the legal requirements associated with these rights.

- Users may download and print one copy of any publication from the public portal for the purpose of private study or research

- You may not further distribute the material or use it for any profit-making activity or commercial gain

- You may freely distribute the URL identifying the publication in the public portal ?

Take down policy

If you believe that this document breaches copyright please contact us providing details, and we will remove access to the work immediately and investigate your claim. 


\title{
People with dementia and caregiver preferences for digital life story work service interventions. A discrete choice experiment and digital survey.
}

\begin{abstract}
Objectives: Little is understood about the optimal way to implement digital life story work (LSW). The aim of this research was to explore the preferences of people with dementia and caregivers in relation to digital LSW, in an effort to improve future engagement.
\end{abstract}

Methods: 67 caregivers responded to an online discrete choice experiment (DCE) survey containing 16 pairwise choices. The DCE was analysed using a random effects logit model. Willingness to pay and odds ratios were also calculated. 17 participants with dementia completed an online survey, in which they made choices about different aspects of digital LSW services.

Results: Caregivers valued four out of five attributes [setting $(p=0.000)$, price $(\mathrm{p}=0.000)$, elementary usability and accessibility $(\mathrm{p}=0.001)$, and follow-up assistance $(p=0.034)]$. In data from participants with dementia, the most preferred setting was individual one-to-one (70.6\%), and the most preferred use of digital life storybooks was to share memories with others (64.7\%). Marginally more participants with dementia said they would pay for the service (53\%) rather than only use it free of charge (47\%). Those with advanced ICT skills preferred to learn how to use the digital life storybook (64.7\%), while those with elementary/intermediate skills, preferred to have it created for them $(35.3 \%)$.

Conclusions: This exploratory study provides an insight into preferences of people with dementia and caregivers, of how digital LSW is implemented. Results can contribute to future planning and tailoring of these services.

Keywords: dementia, digital life story work, preferences, ICT, reminiscence 


\section{Introduction}

In the absence of disease-modifying treatments, the most effective interventions for people with dementia and their caregivers are the development and provision of services to support them (Nolan, Ryan, Enderby, \& Reid, 2002). Life Story Work (LSW) is a popular psychosocial intervention for people with dementia and their caregivers. It involves discussing life experiences and memories with others, and using this information to create some kind of life story record that can benefit the person on an ongoing basis (McKeown, Clarke \& Repper, 2006; Murphy, 2000). LSW is viewed as a person-centred approach, with getting to know the person at its heart (McKeown, Clarke, Ingleton, Ryan, \& Repper, 2010; McKinney, 2017). It can foster understanding of biography, behaviour, and discourse in addition to promoting communication, reinforcing identity, and providing ideas for meaningful occupation (Brooker, 2004; Bruce \& Schweitzer, 2008; Gridley, 2017; McKeown et al., 2010).

Advancements in information and communication technology (ICT) have introduced new possibilities for LSW. Multimedia stimuli such as video, audio narration and music can now be placed alongside traditional text and photographs to create a digital life storybook. Some small studies have found promising evidence that digital LSW can benefit people with dementia in the areas of communication, self-identity, quality of life, mood, and enjoyment (Damianakis, Crete-Nishihata, Smith, Baecker \& Marziali, 2010; Ludwin \& Capstick, 2015; Massimi et al, 2008; Stenhouse, Tait, Hardy, \& Sumner, 2013; Subramaniam \& Woods, 2010 Subramaniam \& Woods, 2016). LSW is typically carried out by 'front-line' health and social care staff, through services/organisations, or within the realms of research. It is relatively popular in residential care settings, but there is evidence that it is helpful in community settings too (Subramaniam \& Woods, 2016; Stenhouse et al., 2013). While LSW services are not currently commonplace in the UK, the growing popularity and positive evidence for the approach is paving the way for the development of services and resources to facilitate this work (e.g. Book of You ${ }^{1}$, Dementia $\mathrm{UK}^{2}$, The Life Story Network ${ }^{3}$ ).

Although LSW appears to be valuable and enjoyable for people living with dementia and caregivers (McKeown et al., 2010; Subramaniam \& Woods, 2010), engagement and uptake remain an issue. For example, in 3- and 6-month follow-ups, Damianakis and

\footnotetext{
${ }^{1}$ www.bookofyou.co.uk

${ }^{2}$ www.dementiauk.org

${ }^{3}$ www.lifestorynetwork.org.uk
} 
colleagues (2009) reported that some participants viewed their digital life storybooks rarely (once per month), despite being asked to view it at least once per week. On the other hand, Subramaniam and Woods (2016) reported that all six participants in their study viewed their digital life storybooks several times per week, with some assistance from care staff to do so. In this study, a completed 'movie' of the person's life story including personal photos, music and narration was prepared for participants, with their input relating to content and formathe term 'life story work' embodies a range of approaches, which can vary in terms of setting, support level, intervention focus, modality, type of life storybook, and intervention aims (Woods \& Subramaniam, 2017). This variation carries through to research and practice making it difficult to understand which aspects of LSW appeal most to people with dementia and their caregivers. As there are so many potential implementations of digital LSW, it is important to understand user preferences so that we can begin to piece together the optimal method of delivery, to improve future engagement in both interventions and services.

One way of eliciting preferences of how services or interventions are delivered is through a discrete choice experiment (DCE). In DCEs, participants make choices between different 'packages' of a good or service. This method draws upon Lancaster's (1966) Economic Theory of Value. It assumes that people obtain value/benefit from the different attributes that make up goods or services, rather than the goods or services as a whole. Therefore, changes to the attributes of a good or service may cause individuals to switch to another good or service that will provide a more beneficial combination of attributes.

Essentially, DCEs draw out the characteristics of a particular product or service that are important to individuals by considering their choices between different goods or services that have varying levels of the same attributes.

The aim of this study was to explore choices made by people living with dementia and their caregivers concerning digital LSW interventions and services. To elicit preferences, we administered an online DCE for caregivers and a simple online survey for people living with dementia. This study aims to address the following research questions:

(1) What features of a digital LSW service intervention are preferred by people with dementia?

(2) What features of a digital LSW service intervention are most important to caregivers or supporters of people with dementia? 


\section{Method}

This study had two arms. In Study 1, participants with dementia completed an online survey regarding their preferences of digital LSW services. In Study 2, caregiver preferences were explored using an online DCE. In both arms, a hypothetical LSW intervention was presented to participants, including a digital life storybook operated through an app.

\section{Ethical approval}

Ethical approval for this research was obtained from the Healthcare and Medical Sciences Academic Ethics Committee at Bangor University.

\section{Study 1}

\section{Participants}

Participants were a convenience sample of people with dementia living in the UK. The inclusion criteria for the study required that participants have the mental capacity to consent to participate (Department of Health, 2005). As the survey was online, participants needed to own, or have access to a computer, tablet computer, or smartphone, in addition to an internet connection. Recruitment took place between the May $17^{\text {th }}$ and July $11^{\text {th }}, 2017$. Participants were offered a $£ 5$ store voucher for taking part in the survey.

Potential participants were primarily identified and contacted through Join Dementia Research (JDR). JDR is a nationwide database of people with dementia, caregivers, and others who are interested in participating in research on dementia. It is operated by the National Institute of Health Research, and matches potential participants with appropriate research studies. Social media and the North Wales Dementia Network were also used to circulate information about the study.

\section{Survey Design}

The survey in Study 1 was modelled on the DCE in Study 2, though it was greatly simplified to avoid the cognitive load of a DCE. Previous qualitative research, exploring the experiences of 12 people with dementia and caregivers of different implementations of a digital LSW service, was used to inform the current survey design (identifying reference removed). Discussions with a LSW service and a clinical psychologist experienced in LSW also contributed to the survey design. The survey comprised 10 questions, and participants could save their progress and return to the study at a later point if they wished to take a break. A progress bar kept participants informed of their progression throughout the survey. 
Procedure

Interested participants were provided with a link to the survey via e-mail. When they clicked the link, they were first presented with the information sheet and a digital consent form. If consent was given, the survey opened. Participants were asked to supply their age and gender, in addition to their self-reported ICT skills and any previous experience with digital LSW. A brief background of LSW and a video describing a LSW service were provided. Respondents were then asked to select their preferred choice of setting, app, usability and accessibility level, price, follow up assistance, and session focus (See Table 1).

\section{Analysis}

Results were analysed in SPSS version 24. Descriptive statistics were used to describe the sample while frequency data were used to illustrate preferences.

\section{Study 2}

Participants

Participants were a convenience sample of caregivers of people with dementia, living in the UK. In this context, caregiver refers to a family member, friend, or professional caregiver who sees the person with dementia regularly. Again, access to the internet and a computer, tablet computer, or smartphone were required. A $£ 5$ store voucher was offered to participants for taking part. Similar to Study One, JDR was the primary recruitment pathway, and study information was also circulated using social media and the North Wales Dementia Network. Recruitment took place between May $17^{\text {th }}$ and July $11^{\text {th }}, 2017$.

\section{Study Design}

The purpose of DCEs is to elicit preferences. They are often used in health economics to explore preferences concerning healthcare products and packages. In a DCE, respondents are asked to make choices between pairs of hypothetical scenarios that describe a good or service. Participants are presented with a pair of scenarios, each with the same attributes, but varying levels of each attribute. For example, the attribute 'price' could have levels of 'no cost', ' $£ 25$ ', and ' $£ 50$ '. The attributes, levels, and definitions pertaining to the current study are presented in Table 1, and an example choice set is shown in Figure 1. Again, previous 
research (anonymised reference), and discussions with an experienced clinical psychologist and LSW service informed the survey design.

The DCE had three attributes with two levels, and two attributes with three levels, resulting in 72 potential choice sets $\left(3^{2} \times 2^{3}\right)$. An orthogonal main effects plan (52a) from a published design catalogue (Hahn \& Shapiro, 1966), was used to reduce this to a manageable number. This 'plan' informs the construction of the choice sets. According to the plan, 16 choice sets were required to ensure orthogonality (showing pairs of levels proportionately often). To determine the necessary sample size, a 'rule of thumb' that each main effect level of interest should be represented across the design at least 500 times, was applied (Orme, 2010). Therefore it was estimated that a two-alternative, forced choice format with 16 choice sets, would require a minimum of 47 participants.

It was not possible to select dominant choice sets (those in which one service contains all preferred attribute levels and the other contains the least preferable levels) for removal, as the intervention was psychosocial and the 'preferred option' was not apparent in most attributes. The DCE did not contain any additional choice sets to test for transitivity, though this was tested to an extent. This was to avoid increasing the cognitive load by adding more choice sets. Here, transitivity implies that if a person chooses one package of choices, they should transitively choose that same package in another choice set where it has at least one additional preferred level of an attribute, and has no inferior levels of the other attributes (McIntosh \& Ryan, 2002). The survey also contained demographic questions and comprised 23 items in total. Again, participants could save their progress and return to the survey if they wanted a break. A progress bar kept participants informed of their progression throughout the survey.

\section{Procedure}

Similar to Study 1, potential participants were directed to the survey through a link, sent via e-mail. They were firstly presented with an information sheet and consent form. If consent was given, the survey opened. Participants were asked to provide their age, gender, current caring situation, and self-reported ICT skills. Again, participants were presented with given general information and a brief video about a LSW service. The definitions of the attributes and levels were presented (Table 1), in addition to instructions and an example of how to complete the DCE. The definition table could be kept open to refer back to if desired.

[Insert Figure 1 near here]

Analysis 
Data were managed in Microsoft Excel (cleaning and organising), SPSS version 24 (descriptive data) and STATA version 13 (DCE data). A random effects logit model was used to analyse the data, and service choice was the dependent variable.

$$
U=\beta_{0}+\beta_{1} \text { setting }+\beta_{2} \text { price }+\beta_{3} \text { usability }+\beta_{4} \text { followup }+\beta_{5} \text { focus }+\varepsilon
$$

$\mathrm{U}=$ utility derived by individual

$\beta_{0}=$ constant term

$\beta_{i}=$ estimated coefficient for each attribute

$\varepsilon=$ error term

It was hypothesised that respondents would prefer an individual setting, a low price, a followup LSW session and written guidance manual, elementary accessibility and usability, and the session focus to involve learning how to use the app. Binary variables were dummy coded and effects coding was used to input categorical attributes (i.e. accessibility \& usability) and to test the assumption of linearity for price. As 'app accessibility and usability' had three levels, one level was selected as a 'base case' and omitted from the model. The coefficient of the omitted level was calculated by multiplying $-\&$ by the sum of the estimated coefficients of the other two levels. As price is a value attribute, it was coded using the value of each level (i.e. $0,25,50)$. The assumption that price was linear was formally tested using effects coding and plotting the resulting size of the coefficient against the level of each attribute (Payne et al. 2011). Level coding is presented in Table 1. Confidence intervals for coefficients were estimated using non-parametric bootstrapping methods (Phillips, Maddala \& Johnson, 2002). A simulation of 1000 non-parametric bootstrapping iterations was run in order to create $95 \%$ confidence intervals around the $\beta$ coefficient.

The $\beta$ coefficient values were used to estimate the relative importance of each attribute. The p-value and magnitude of the coefficient were used to represent the degree of preference for each of the attributes. The sign of the coefficient was used to determine which level of the attribute was preferred (only where attributes had two levels and were non-value). The marginal rate of substitution (MRS) between price and other (statistically significant) attributes were then analysed. The MRS represents the amount of money the respondent was willing to pay for one level of an attribute over another. The same non-parametric bootstrapping method was used to create $95 \%$ confidence intervals around the MRS estimates 
(Phillips et al, 2002). Each coefficient was exponentiated and reported as an odds ratio. Odds ratios greater than 1 represent positive utilities, whereby respondents have given more importance to the attribute level. Negative odds ratios between 0 and 1, represent a lower probability of a respondent choosing an alternative when this attribute level is shown.

The influence of participant age, ICT skills, and caregiving situation on preferences was assessed using exploratory subgroup analyses. Log likelihood ratio tests of the base case regression and the models comprising the two subgroups were performed at a 5\% level of significance with Bonferroni correction for multiple comparison $(p=0.017)$. Subgroup analyses of gender and previous experience of LSW services were not possible due to the distribution of participants across the subgroups.

\section{Results}

\section{Study 1 (Participants with dementia)}

All questionnaires were completed fully, with the exception of one in which 9/10 questions were answered. Characteristics of participants with dementia are outlined in Table 2.

\section{[Insert Table 2 near here]}

\section{Survey responses}

Most participants with dementia (71\%) responded that they would prefer the intervention setting to be one-to-one in their home, rather than in a community group (29\%). Almost twothirds $(65 \%)$ wanted to focus on learning how to use the app while being supported to create their own digital life storybook during the sessions. However, only participants with selfreported advanced ICT skills chose this option. Just over one-third (35\%) chose the alternative option of having the service build their life storybook for them under their instruction. Of these participants, three had elementary, and two had intermediate self-rated ICT skills. Nearly two thirds (65\%) of participants indicated that they would mainly use their digital life storybook 'to look at with family and friends, and enjoy shared memories', while the remaining responses were split evenly between "to look at on my own and enjoy memories and music" (17.5\%) and "to show to new people to help them to understand my life experiences and interests" (17.5\%). When five attribute levels were presented together (see Table 3), 'being taught how to use the digital life storybook and being helped to create my digital life storybook was the most popular choice (41\%), followed by 'doing life story work individually in my home' (23.5\%), and 'having the service build my life storybook for me while I tell them what to put in it' (17.6\%). The two least popular attribute levels were 
'being given a written guidance manual on how to use the book after the workshops are finished' (11.8\%) and 'doing life story work in a group in a community centre or library' (5.9\%). When presented with three price options for a six-week digital LSW service, marginally more participants said they would pay for the service (53\%), than only use it free of charge (47\%). Of those who responded that they would pay for the service, most (78\%) indicated that they would consider a small amount such as $£ 25$, while $22 \%$ would consider a more significant sum such as $£ 50$.

\section{[Insert Table 3 near here]}

\section{Caregivers}

The analysis included all completed surveys. A completed survey was defined as at least $50 \%$ of the choice sets being completed. Three participants did not respond to all 16 choice sets but completed 15, 8, and 15 choice sets respectively. Therefore, the final analysis was comprised of data from all 67 caregivers. Missing data were not imputed. Caregiver characteristics are presented in Table 4. The sample was predominantly female, and most participants had advanced self-reported ICT skills. One participant responded 'other' to the question about their caregiving situation but did not elaborate further. Two participants had previous experience with LSW. One had seen a presentation about it, while the other had encountered traditional LSW through a supported living association.

Assessment of level dominance within a given attribute showed 12 respondents always selected the service provided on a one-to-one basis while three always chose the service that included both a manual and follow up workshop. No respondents demonstrated lexicographic preferences for Service A or Service B. Assessment of transitivity showed that 18 respondents always selected the cheapest service.

\section{[Insert Table 4 near here]}

\section{Preferences for digital LSW services, magnitude and statistical significance of results.}

Table 5 shows the results of the estimated regression model. All attributes were in the direction of the a-priori hypotheses. Participants had strong and statistically significant preferences for the intervention setting, preferring it to take place one-to-one at home rather than in a community group $(\beta=-) .802 ; \mathrm{p}=0.000)$. Price was the only attribute entered as a continuous variable. Participants preferred to pay a lower price for the service, evidenced by 
the negative direction of the coefficient $(\beta=-) .019 ; p=0.000)$. Testing of effects coding confirmed the assumption of linearity (Figure 2). Regarding app accessibility and usability (see Table 1 for outline of the levels of this attribute), participants preferred an app that was of elementary usability and accessibility $(\beta=0.180 ; p=0.001)$. The intermediate level of the accessibility and usability attribute was not statistically significant $(\beta=0.000 ; p=0.998)$. As the advanced level of this attribute was the base case in the effects coding, it was not possible to generate a p-value. However, as the confidence interval passed 0 in one of the other levels, it is likely that the advanced level was not significant. Follow-up assistance was a statistically significant driver of preferences, with an additional follow-up LSW session and a guidance manual being preferred to a manual alone $(\beta=-0.150 ; p=0.034)$. The co-efficient for session focus was small and not significant $(\beta=-0.032 ; p=0.651)$. The constant term was positive and significant, suggesting that respondents were considering other attributes not included in the current DCE $(\beta=0.164 ; p=0.023)$. MRS values of willingness to pay are also presented in Table 5. These are the values that respondents place on each attribute, relative to price. Setting was the most important attribute relative to price, with caregivers willing to pay an additional $£ 41.45$ for a service in an individual setting rather than a community group. The MRS on the advanced level of the accessibility and usability attribute indicates that participants would pay $£ 9.31$ less for the service if this was the case. Participants were willing to pay an additional $£ 7.75$ to have a follow-up session in addition to a guidance manual, rather than a manual alone.

\section{[Insert Figure 2 near here]}

When the odds ratios (OR) are interpreted (Table 5), a service in an individual setting was preferred twice as much as a service in a group setting, all else being equal $(\mathrm{OR}=0.45)$. Price had an odds ratio of 0.98 , with participants showing a marginal preference for less expensive interventions. When app usability and accessibility was elementary, this was preferred to the alternative advanced level $(\mathrm{OR}=1.20)$, while intermediate usability and accessibility had equal odds $(\mathrm{OR}=1)$ to the advanced alternative. In follow-up support, the odds of preferring one service over another increased by 0.14 , when a follow-up manual and an additional LSW session were provided. For session focus, the odds of choosing a service that trains people to use the app, and supports them to create their own digital life storybook were marginally higher than the alternative of having their book built for them $(\mathrm{OR}=0.97)$.

[Insert Table 5 near here] 
The likelihood-ratio test for models accounting for age ( $<56$-years/ $\geq 56$ years) indicated the base case model was statistically different from the model comparing the two subgroups $(\mathrm{p}=0.013)$. In the subgroup analysis, there were no significant differences in willingness to pay for: setting, accessibility and usability, and follow-up assistance (confidence intervals around MRS overlap). There is, however, a statistically significant difference in willingness to pay for session focus. The MRS on the session focus attribute for older participants indicates they were willing to pay an additional $£ 13.30$ if the session also taught them how to use the app (Table 6). Likelihood ratio tests for models accounting for ICT skills $(p=0.554)$ and caregiving situation $(p=0.058)$ were not significantly different to the base case.

\section{[Insert Table 6 near here]}

\section{Discussion}

This is one of the first studies to explore the preferences of people living with dementia and caregivers, in relation to digital LSW. Through a discrete choice experiment, four attributes that significantly shaped family caregiver preferences were identified. When ranked, the intervention setting had the most influence on caregiver preferences, followed by elementary app usability and accessibility, follow-up assistance, and the price of the intervention. Using an online survey of people with dementia, preferred features of digital LSW services in to relation setting, session focus, price, and planned future use of digital life storybooks were identified.

The intervention setting had the most significant influence on caregiver preferences, to the extent that they were willing to pay an additional $£ 41.45$ to have the intervention take place one-to-one in their homes, rather than in a group setting. Furthermore, they were twice as likely to pick a service in an individual setting than the alternative group setting. Similarly, among participants with dementia, the individual setting was more popular than the community group setting. However, it is important not to disregard group-based LSW, as almost one-third of participants with dementia indicated that they would prefer this over the individual option. In previous research, positive outcomes of digital LSW have been identified in both individual and group settings among community (Massimi et al., 2008; Stenhouse et al., 2013), and care home residents (Damianakis et al., 2010; Ludwin \& Capstick, 2015; Subramaniam \& Woods, 2016). Similarly, a previous qualitative study found that participants in a digital LSW group felt the social aspect of the groups was the main 
benefit, while those in individual settings discussed the benefits of LSW itself, and couldn't see how it would be feasible in a group setting (O' Philbin et al., 2017).

Learning how to use the app while being supported to create their own digital life storybook was the most popular choice of session focus among participants with dementia. However, only those who reported having advanced ICT skills selected this option. Those with elementary or intermediate skills chose the alternative option; to dictate the content of their digital life storybook and have the service create it for them. This is similar to a previous study of a supported digital LSW intervention with people with dementia (Stenhouse et al, 2013). They observed that participants did not want to interact with ICT to create their digital life storybook, and instead, dictated the content to the researcher who created the digital life story book for them. Similarly, Mulvenna and colleagues (2017) observed that caregivers acted as 'admins' and added reminiscence stimuli to the app, while participants with dementia mostly used the app to reminisce. Although session focus was not a significant attribute in the overall caregiver model, when older ( $\geq 56$ years) and younger ( $<56$ years) participants' willingness to pay was compared, there was a significant difference. Older participants were willing to pay an additional $£ 13.30$ if they were also taught how to use the app in the session; while the younger group would pay $£ 12.80$ less if the session involved this. Elementary accessibility and usability (relative to advanced) of the digital life storybook app was a significant driver in caregiver preferences. The analysis showed that caregivers were willing to pay an additional $£ 9.31$ to avoid an app that required more advanced skills to create a digital life storybook (see Table 1 for information about this attribute). This echoes a previous study in which ICT was found to be a significant barrier for all participants with dementia, while caregivers struggled with the more advanced aspects of the app such as adding video and music despite some having intermediate to advanced selfreported ICT skills (O’ Philbin et al., 2017).

The majority of participants with dementia selected the 'free' price option, but when the two 'paying' options (i.e. $£ 25$ and $£ 50$ ) were combined, it emerged that marginally more indicated that they would contribute to the costs of the LSW service. Although the price was a significant driver of caregiver preferences with a lower price being preferred, the odds ratio showed that this was marginal. To our knowledge, the attitudes of people with dementia and caregivers towards paying or contributing to LSW services are not explored elsewhere in the literature.

The level of follow-up support provided by the LSW service was a significant driver in caregiver preferences, with a follow-up session and guidance manual being preferred to a 


\section{Limitations}

A clear limitation of this study is the lack of comparability between responses in the online survey for participants with dementia, and the DCE for caregivers. DCEs are associated with a high cognitive load, so the survey for people with dementia was simplified to prevent this. The sample of participants with dementia is small, and the recruitment process means that it is probably not representative of the wider population of people living with mild to moderate dementia and caregivers. Similarly, collecting data online meant that the preferences of people who may want to explore digital LSW but who currently do not use ICT were not considered, while current participants likely had some degree of ICT skill. Although the caregiver sample is a reasonable size and exceeds the minimum required number of participants, sub-group analyses were limited due to the distribution of participants across sub-groups. Only a limited number of attributes could be included, which is a general drawback of DCEs due to limitations in the amount of information people can process. 


\section{Implications and Future Research}

The results of this exploratory work can serve as a practical tool for organisations and services to use in combination with other research and user consultation to plan digital LSW interventions. Results offer insight into preferences of people living with dementia and caregivers in relation to digital LSW, and provide some groundwork for more in-depth and thorough investigation. The importance of considering user ICT skills, and tailoring the intervention to these skills from the outset is clear.

More research with larger sample sizes is needed to explore aspects of digital LSW interventions that are important to people with dementia and caregivers. Relatively few DCEs have been conducted with people with dementia and caregivers of people with dementia, and more work is needed to validate this method with this group. In future research, ideally, both people with dementia and caregivers would complete a DCE survey, so that results can be compared. Carrying out a shorter DCE in a supported setting with a researcher could help to alleviate the cognitive load associated with this method. As there is evidence to show that digital LSW can be valuable in care home settings (e.g. Damianakis et al., 2010;

Subramaniam \& Woods, 2016), preferences among care home residents, staff, and relatives should also be explored.

\section{Conclusion}

This exploratory study provides initial insights into preferences of digital LSW services among people with dementia and caregivers. Results suggest that most (but not all) participants with dementia prefer an individual intervention setting, and would use their digital life storybooks to share memories with family and friends. Marginally more participants would pay for the service than use it free of charge, while self-reported ICT skills dictated their preference for the focus of the LSW sessions. The results of the DCE show that an individual intervention setting, a low price, a digital life story book that is simple to use, and an additional follow-up session are important to caregivers.

\section{References}


Brooker, D. (2003). What is person-centred care in dementia? Reviews in Clinical Gerontology, 13(3), 215-222.

Damianakis, T., Crete-Nishihata, M., Smith, K. L., Baecker, R. M., \& Marziali, E. (2010). The psychosocial impacts of multimedia biographies on persons with cognitive impairments. The Gerontologist, 50(1), 23-35.

Department of Health. (2005). Mental capacity act. London: HMSO.

Gridley, R. (2016). Understanding the outcomes of life story work. In P. Kaiser, \& R. Eley (Eds.), Life story work with people with dementia: Ordinary lives, extraordinary people (pp. 69-82). Philadelphia: Jessica Kingsley Publishers.

Hahn, G. J., \& Shapiro, S. S. (1966). A catalog and computer program for the design and analysis of orthogonal symmetric and asymmetric fractional factorial experiments (1st ed.). Schenectady, New York: General Electric, Research and Development Center.

Lancaster, K. (1966). A new approach to consumer theory. Journal of Political Economy, 74(2), 132-57.

Ludwin, K., \& Capstick, A. (2015). Using participatory video to understand diversity among people with dementia in long-term care. Journal of Psychological Issues in Organizational Culture, 5(4), 30-38.

Massimi, M., Berry, E., Browne, G., Smyth, G., Watson, P., \& Baecker, R. M. (2008). An exploratory case study of the impact of ambient biographical displays on identity in a patient with alzheimer's disease. Neuropsychological Rehabilitation, 18(5), 742-765.

McKeown, J., Clarke, A., Ingleton, C., Ryan, T., \& Repper, J. (2010). The use of life story work with people with dementia to enhance person-centred care. International Journal of Older People Nursing, 5(2), 148-58. 
McKeown, J., Clarke, A., \& Repper, J. (2006). Life story work in health and social care: Systematic literature review.Journal of Advanced Nursing, 55(2), 237-247.

McKinney, A. (2017). The value of life story work for staff, people with dementia and family members. Nursing Older People, 29(5), 25.

Mulvenna, M., Gibson, A., McCauley, C., Ryan, A., Bond, R., Laird, L., . . Ferry, F. ( 2017, September). Behavioural usage analysis of a reminiscing app for people living with dementia and their carers. Paper presented at the European Conference on Cognitive Ergonomics 2017, Umea, Sweeden. ACM Digital Library.

Murphy, C. (2000). Crackin' lives: An evaluation of a life story-book project to assist patients from a long stay psychiatric hospital in their move to community care situations. Dementia Services Development Centre, Stirling.:

Nolan, M., Ryan, T., Enderby, P., \& Reid, D. (2002). Towards a more inclusive vision of dementia care practice and research. Dementia, 1(2), 193-211.

O’Philbin, L., Woods, B., Barham, K. \& Windle, G. (2017). 153 Implementing Digital Life Story Work for People with Dementia: The Relevance of Context to User Experience. Age and Ageing, 46 (Suppl_3), iii12.

Orme, B. K. (2010). Getting started with conjoint analysis (2. ed. ed.). Madison, Wis: Research Publ.

Payne, K., Fargher. E. A., Roberts, S.A., Tricker, K., Elliott, R.A., Ratcliffe, J., Newman, W.G. (2011). Valuing pharmacogenetic testing services: a comparison of patients' and health care professionals' preferences. Value in health, 14(1), 121-34. 
Phillips, K. A., Maddala, T., \& Johnson, F. R. (2002). Measuring preferences for health care interventions using conjoint analysis: An application to HIV testing. Health Services Research, 37(6), 1681-1705.

Ryan, M., Gerard, K., \& Amaya-Amaya, M. (2008). Using discrete choice experiments to value health and health care. Dordrecht: Springer.

Stenhouse, R., Tait, J., Hardy, P., \& Sumner, T. (2013). Dangling conversations: Reflections on the process of creating digital stories during a workshop with people with early-stage dementia. Journal of Psychiatric and Mental Health Nursing, 20(2), 134-141.

Subramaniam, P., \& Woods, B. (2010). Towards the therapeutic use of information and communication technology in reminiscence work for people with dementia: A systematic review. International Journal of Computers in Healthcare, 1(2), 106-125.

Subramaniam, P., \& Woods, B. (2016). Digital life storybooks for people with dementia living in care homes: An evaluation. Clinical Interventions in Aging, 11, 1263-1276.

Woods, B, \& Subramaniam, P. (2017). The evidence base for lifestory work so far. In P. Kaiser, \& R. Eley (Eds.), Life story work with people with dementia: Ordinary lives, extraordinary people (pp. 83-96). London: Jessica Kingsley Publishers. 
Table 1. Attributes, levels, definitions and coding

\begin{tabular}{|c|c|c|}
\hline Attributes & Levels & Level description and coding () \\
\hline \multirow[t]{2}{*}{ Setting } & Group & $\begin{array}{l}\text { The workshop is in a small group of 6-8 people with dementia and caregivers. It takes place in a community setting } \\
\text { such as a room in a community centre or library. A volunteer from the service facilitates the workshop (1) }\end{array}$ \\
\hline & One to one & $\begin{array}{l}\text { The workshop is done with one person with dementia and their caregiver (if they wish). It takes place in home of the } \\
\text { person with dementia/caregiver. A volunteer from the service facilitates the workshop ( } 0 \text { ) }\end{array}$ \\
\hline \multirow{3}{*}{ Price } & Free & You do not pay for the service $(0)$ \\
\hline & $£ 25$ & You pay $£ 25$ in total for the service lasting 6 weeks for 2 hours per week (25) \\
\hline & $£ 50$ & You pay $£ 50$ in total for the service lasting 6 weeks for 2 hours per week (50) \\
\hline \multirow{3}{*}{$\begin{array}{l}\text { App } \\
\text { accessibility } \\
\text { and usability }\end{array}$} & Advanced & $\begin{array}{l}\text { The app usability is advanced. The skill level needed is similar to downloading apps, setting up programmes such as } \\
\text { Dropbox, and configuring settings (base case) }\end{array}$ \\
\hline & Intermediate & $\begin{array}{l}\text { The app usability is intermediate. The skill level needed is similar to that of online shopping, playing games and using } \\
\text { e-mail. }\end{array}$ \\
\hline & Elementary & The app is simple to use. You need IT skills similar to those needed to use Facebook and view news articles online \\
\hline \multirow{2}{*}{ Follow Up } & Manual only & When you finish the workshops, you are given a written detailed guide on how to use Book Of You (1) \\
\hline & Manual and follow up & $\begin{array}{l}\text { When you finish the workshops, you are given a detailed written guide on how to use Book of You and you have a } \\
\text { one hour follow up workshop with the same volunteer }(0)\end{array}$ \\
\hline \multirow{2}{*}{ Session Focus } & Book only & The volunteer makes a digital life storybook for you during the workshops while you dictate the content (1) \\
\hline & $\begin{array}{l}\text { Book \& learn how to } \\
\text { use app }\end{array}$ & A volunteer works with you to teach you how to use the app and help you to build your digital life storybook (0) \\
\hline
\end{tabular}


Table 2. Characteristics of participants with dementia

\begin{tabular}{ll}
\hline Characteristics & $\mathrm{N}(\%)$ or Mean $(\mathrm{SD})$ \\
\hline $\mathrm{N}$ & 17 \\
Age & $61.65(12.33)$ \\
Gender & \\
$\quad$ Male & $8(47.1)$ \\
$\quad$ Female & $9(52.9)$ \\
Self-reported IT skills & \\
$\quad$ Elementary & $3(18.8)$ \\
$\quad$ Intermediate & $2(12.5)$ \\
Advanced & $11(68.8)$ \\
Have you ever used a LSW service before? & $2(11.8)$ \\
Yes, a digital service & $1(5.9)$ \\
Yes, a non-digital service & $0(0)$ \\
Both a digital and non-digital service & $14(82.4)$ \\
No & $0(0)$ \\
Other & \\
\hline
\end{tabular}


Table 3. Survey responses of participants with dementia

\section{Characteristics}

Setting preference

Private one-to-one at home

Community Group

Session focus preference

Service builds a life story book for me with my instruction

Learn how to use the app and be supported to build my own life story book

I would mostly use my digital life story book

To look at on my own and enjoy memories and music

To look at with family and friends and enjoy shared memories

To show to new people to help them understand my life experiences and interests

Most important thing when doing life story work

Doing Life Story Work in a group in a community centre or library

Doing Life Story Work individually in my home

Having the service build my life storybook for me while I tell them what to put in it

Being taught how to use the digital life story book and being helped to create my digital book

Being given a written instruction guide on how to use the book after the workshops are finished

Paying for the service (6 sessions, 2 hours each)

I would only use it free of charge

$£ 25$

$£ 50$ 
Table 4. Characteristics of caregiver respondents

\begin{tabular}{ll}
\hline Characteristics & $\mathrm{N}(\%)$ or Mean (SD) \\
\hline $\mathrm{N}$ & 67 \\
Age & $54.12(16.34)$ \\
Gender & \\
$\quad$ Male & $11(16.4)$ \\
$\quad$ Female & $56(83.6)$ \\
& \\
Caregiving Situation & \\
The person I care for lives in residential care & $22(32.8)$ \\
The person I care for lives with me & $20(29.9)$ \\
The person I care for lives at home but not with & $24(35.8)$ \\
me & \\
Other & \\
& \\
Self-reported IT skills & \\
Elementary & $2(3.0)$ \\
Intermediate & $27(40.9)$ \\
Advanced & $37(56.1)$ \\
& \\
Have you ever used a LSW service before? & $1(1.5)$ \\
Yes, a digital service & $61(91)$ \\
Yes, a non-digital service & $2(3.0)$ \\
Ooth a digital and non-digital service & \\
Other & \\
\hline
\end{tabular}


Table 5. Results of the random-effects logit regression model

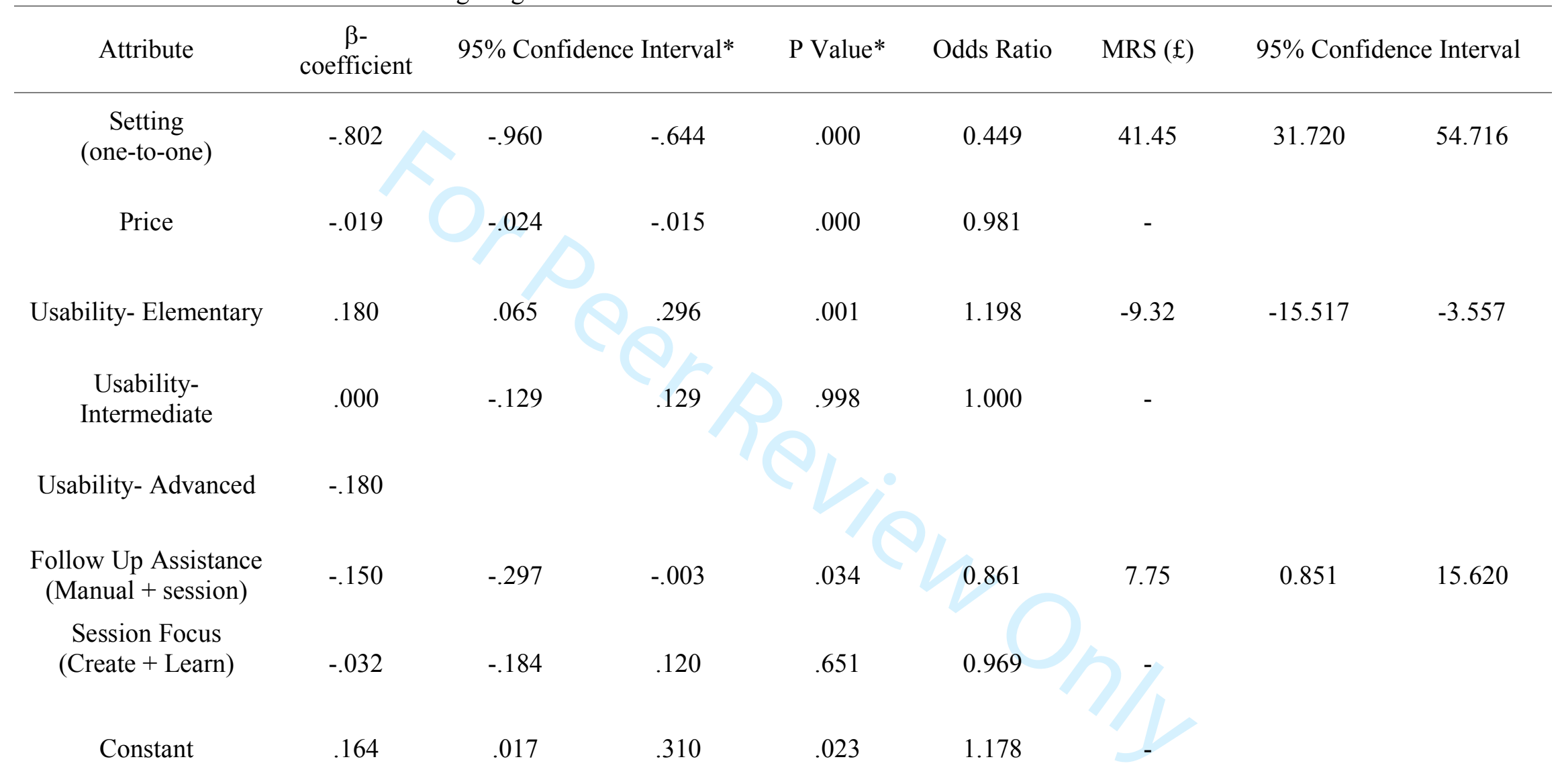

No. observations $=1062 ;$ No. individuals $=67 ;$ Wald chi2 $(6)=181.56 ; \log$ likelihood $=-609.96778$

*Statistically significant at $\mathrm{p}<0.05$

95\% confidence intervals generated using non-parametric bootstrapping

Price base case (advanced) calculated by assuming estimate for effects coded omitted variable $=-1$ (sum of estimated levels)

Marginal rate of substitution values $=\beta$-coefficient for significant attribute $/ \beta$-coefficient for price 
Table 6. Results of the unrestricted random-effects logit regression model for age

\begin{tabular}{|c|c|c|c|c|c|c|c|c|c|c|c|c|c|c|}
\hline \multirow{3}{*}{$\begin{array}{l}\text { Attribute } \\
\text { Setting }\end{array}$} & \multicolumn{7}{|c|}{ Younger Age $(<56$ years) } & \multicolumn{7}{|c|}{ Older Age ( $\geq 56$ years) } \\
\hline & \multirow{2}{*}{$\begin{array}{c}\beta \text {-coef. } \\
-0.847\end{array}$} & \multicolumn{2}{|c|}{$\begin{array}{l}\text { 95\% Confidence } \\
\text { Interval* }\end{array}$} & \multirow{2}{*}{$\begin{array}{c}\begin{array}{c}\mathrm{P} \\
\text { Value* }\end{array} \\
0.000\end{array}$} & \multirow{2}{*}{$\begin{array}{c}\begin{array}{c}\text { MRS } \\
(£)\end{array} \\
48.417\end{array}$} & \multicolumn{2}{|c|}{$\begin{array}{l}\text { 95\% Confidence } \\
\text { Interval* }\end{array}$} & \multirow{2}{*}{$\begin{array}{c}\beta \text {-coef. } \\
-0.779\end{array}$} & \multicolumn{2}{|c|}{$\begin{array}{l}\text { 95\% Confidence } \\
\text { Interval* }\end{array}$} & \multirow{2}{*}{$\begin{array}{c}\begin{array}{c}\mathrm{P} \\
\text { Value* }\end{array} \\
0.000\end{array}$} & \multirow{2}{*}{$\begin{array}{c}\begin{array}{c}\text { MRS } \\
(\mathfrak{f})\end{array} \\
35.768\end{array}$} & \multicolumn{2}{|c|}{$\begin{array}{l}95 \% \text { Confidence } \\
\text { Interval* }\end{array}$} \\
\hline & & -1.137 & -0.698 & & & 33.453 & 72.175 & & -1.081 & -0.625 & & & 24.949 & 51.738 \\
\hline Price & -0.017 & -0.025 & -0.012 & 0.000 & 1.000 & & & -0.022 & -0.031 & -0.018 & 0.000 & & & \\
\hline $\begin{array}{l}\text { Usability- } \\
\text { Elem. }\end{array}$ & 0.013 & -0.170 & 0.196 & 0.883 & & -11.342 & 9.065 & -0.011 & -0.196 & 0.165 & 0.902 & & -7.406 & 8.436 \\
\hline $\begin{array}{l}\text { Usability- } \\
\text { Inter. }\end{array}$ & 0.163 & 0.006 & 0.342 & 0.043 & -9.297 & -20.040 & -0.398 & 0.200 & 0.054 & 0.385 & 0.012 & -9.193 & -17.575 & -2.400 \\
\hline $\begin{array}{l}\text { Usability- } \\
\text { Adv. }\end{array}$ & & & & & & & & & & & & & & \\
\hline $\begin{array}{l}\text { Follow Up } \\
\text { Assistance }\end{array}$ & -0.199 & -0.431 & 0.008 & 0.047 & 11.400 & -0.559 & 24.897 & -0.108 & -0.335 & 0.090 & 0.290 & & -3.796 & 13.385 \\
\hline $\begin{array}{l}\text { Session } \\
\text { Focus }\end{array}$ & 0.224 & 0.037 & 0.447 & 0.026 & -12.832 & -27.187 & -1.949 & -0.289 & -0.545 & -0.103 & 0.004 & 13.297 & 4.225 & 24.035 \\
\hline \multirow[t]{2}{*}{ Constant } & 0.161 & -0.034 & 0.373 & 0.115 & & & & 0.164 & -0.048 & 0.377 & 0.112 & & & \\
\hline & \multicolumn{7}{|c|}{$\begin{array}{l}\text { No. observations }=528 ; \text { No. individuals }=33 ; \text { Wald } \operatorname{chi} 2(6)=95.68 ; \\
\text { Log likelihood }=-300.18\end{array}$} & \multicolumn{7}{|c|}{$\begin{array}{l}\text { No. observations }=534 ; \text { No. individuals }=34 ; \text { Wald } \operatorname{chi} 2(6)=92.20 \\
\text { Log likelihood }=-301.72\end{array}$} \\
\hline
\end{tabular}

*Statistically significant at $\mathrm{p}<0.05$

95\% confidence intervals generated using non-parametric bootstrapping

Price base case (advanced) calculated by assuming estimate for effects coded omitted variable $=-1$ (sum of estimated levels)

Marginal rate of substitution values $=\beta$-coefficient for significant attribute $/ \beta$-coefficient for price 


\section{Figure titles}

Figure 1. Example of the DCE choice set

Figure 2. Test for linearity with price coded as a categorical attribute 
Figure 1. Example of DCE choice set $366 \times 203 \mathrm{~mm}(72 \times 72$ DPI $)$ 


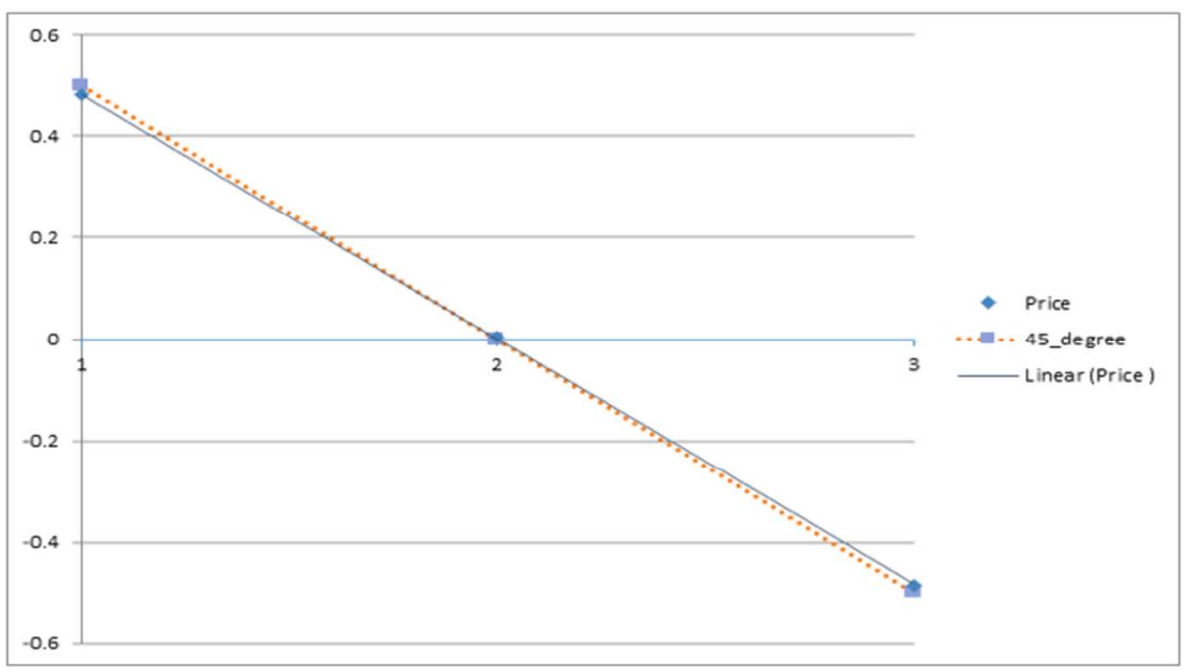

Figure 2. Test for linearity with price coded as a categorical attribute $271 \times 158 \mathrm{~mm}(72 \times 72$ DPI $)$ 